\title{
Reconstruction of northeast Asia spring temperature 1784-1990
}

\author{
M. Ohyama ${ }^{1}$, H. Yonenobu ${ }^{2}$, J.-N. Choi ${ }^{3}$, W.-K. Park ${ }^{4}$, M. Hanzawa ${ }^{1}$, and M. Suzuki ${ }^{1}$ \\ ${ }^{1}$ Botanical Gardens, Tohoku University, Sendai, 980-0862, Japan \\ ${ }^{2}$ College of Education, Naruto University of Education, Naruto 772-8502, Japan \\ ${ }^{3}$ Department of Geography, Western Illinois University, Macomb, IL 61455, USA \\ ${ }^{4}$ School of Forest Resources, Chungbuk National University, Cheongju, 361-763, South Korea \\ Correspondence to: M. Ohyama (motonari@m.tohoku.ac.jp)
}

Received: 6 July 2012 - Published in Clim. Past Discuss.: 14 August 2012

Revised: 9 January 2013 - Accepted: 9 January 2013 - Published: 30 January 2013

\begin{abstract}
We describe a first attempt of wide-area dendroclimatic reconstruction, based upon seven spring temperaturesensitive chronologies from the ring widths of living trees, in Japan and Korea. Mean March-May temperature derived from a gridded land air temperature dataset (CRUTEM4) between $35-40^{\circ} \mathrm{N}$ and $125-140^{\circ} \mathrm{E}$ was reconstructed for the period of AD 1784-1990. Of the seven, two Japanese chronologies were eliminated during the calibration trials. The reconstruction accounted for $19.4 \%$ of the temperature variance in the calibration period, and is considered to be skillful for estimating interannual-to-interdecadal variations and not for long-term change. This reconstruction showed remarkably similar fluctuations to regional dendroclimatic reconstructions in Japan and Korea, indicating the past spatial coherency of spring temperatures in the region. The reconstruction was validated against other climate proxies. A fairly good agreement was found with cold periods as estimated from documentary records in southeast China and Japan. The west Japan temperature series recovered from instrumental records also showed a reasonable agreement with the reconstruction. On the other hand, the reconstruction did not show clear abrupt depressions after the Laki and the Tambora eruptions. These comparisons revealed that dendroclimatic spatial reconstruction in this area offers a good potential for reconstructing long-term and large-scale past temperature patterns for northeast Asia.
\end{abstract}

\section{Introduction}

The East Asian monsoon (hereafter EAM) is an important component of the earth's climate system, and influences the societal and economic activity of one quarter of the world's population. In addition to studies of instrumental data, a dense network of long-term palaeoclimatic records (e.g. documentary records and dendroclimatic reconstructions) is crucial in order to better understand the EAM. In East Asia, documentary reconstructions have demonstrated regional/widearea climate conditions (e.g. temperature and pressure patterns) in the late Little Ice Age (e.g., Maejima and Tagami, 1983; Hirano and Mikami, 2007; Ge et al., 2007). Zaiki et al. (2006) recovered instrumental temperature records before official meteorological observations in Japan and extended these back to 1820 in western Japan.

Dendroclimatic reconstructions using climatically sensitive chronologies, however, are sparse for the mid-latitude East Asian Pacific rim despite recent efforts to improve their coverage (Choi et al., 1994; Gostev et al., 1996; Davi et al., 2002; Jacoby et al., 2004; Yonenobu and Eckstein, 2006; Zhu et al., 2009). Although those recent studies provide regional temperature proxies, spatial temperature reconstruction has never been reported in this region.

The purpose of the present study is to reconstruct the regional-scale spring temperature for northeast Asia, using a network of spring temperature-sensitive regional tree-ring chronologies, including a new tree-ring record from northeastern Japan. The potential of this reconstruction is evaluated in comparison to other proxy-based reconstructions for northeast Asia. 


\section{Data and analysis}

\subsection{Meteorological data}

A gridded land air temperature dataset (CRUTEM4) (Jones et al., 2012) was used. We selected the dataset from $5^{\circ}$ latitude/longitude grids between $30-45^{\circ} \mathrm{N}$ and $125-145^{\circ} \mathrm{E}$ for analysis (shown by dotted lines in Fig. 1). An average land air temperature dataset from the grids with blue lines between $35-40^{\circ} \mathrm{N}$ and $125-140^{\circ} \mathrm{E}$ (Fig. 1) was finally used to obtain an optimal reconstruction model after the calibration trials.

\subsection{Tree-ring records}

We used a total of seven ring-width chronologies to examine the performance of the calibration models. As shown in Table 1, six of these were derived from previous studies (Kojo, 1987; Choi et al., 1994; Yonenobu and Eckstein, 2006). To improve the spatial coverage, we developed a new ring-width chronology of Japanese cedar (Cryptomeria japonica) in northeastern Japan for the period of 1784-2003. The chronology was proven to have sufficient quality and to be sensitive to spring temperature based on a dendroclimatic analysis (Table S1, Fig. S1). The six other series are likewise all sensitive to spring temperature. Because of their unsubstantial coherency with the other records, JAPA001 and 007 were eliminated during the calibration trials. Visual comparison of the remaining five chronologies over the calibration period (1887-1990) is shown in Fig. S2, displaying a temporal coherency between each other. After calculating the principal components (PCs) for the remaining five chronologies over their common interval (1784-1990), PC1 and PC2 (with eigenvalues $>1$ ) were used for reconstruction.

\subsection{Calibration and verification}

Simple correlation analysis was performed between the PCs and the averaged temperature between 1887 and 1990. Based on this correlation analysis, principal component regression (PCR) was performed to derive a transfer function. All mean temperature subsets (February-May) were examined as candidate predictants. Finally, we obtained an optimal calibration model for estimating March-May mean land temperature over the $35-40^{\circ} \mathrm{N}, 125-140^{\circ}$ E region (blue rectangles in Fig. 1).

Since some divergence was observed between the actual and estimated CRUTEM4 data during the calibration trials, a frequency range higher than approximately $60 \mathrm{yr}$ was removed by subtracting a high-pass filtered curve from the original data to remove the upward trend in the actual data series. This filtering enabled the estimated CRUTEM4 data to pass the verification test described in the following paragraph..

The model was further examined using a split period calibration/verification method between 1887-1938 and 19391990. The full 1887-1990 period was used to develop the fi-

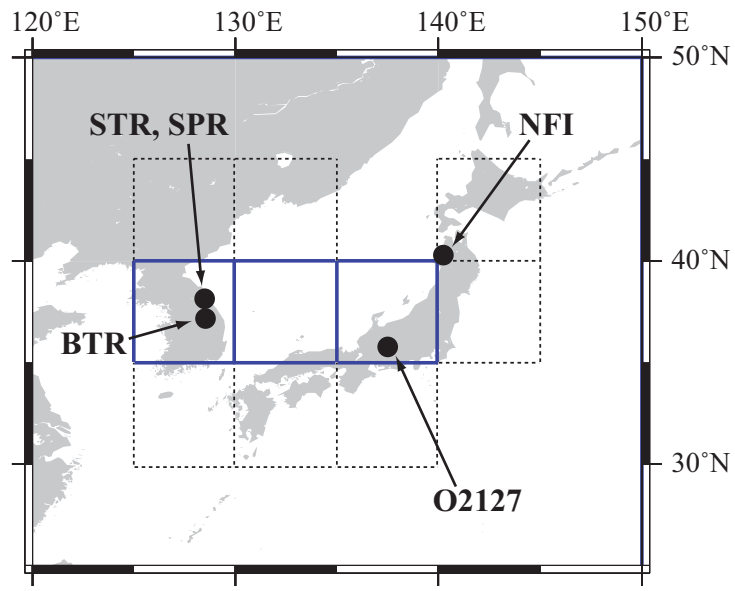

Fig. 1. Map of northeast Asia. Black dots indicate forest sites used for the final calibration. STR, SPR, BTR (Choi et al., 1994), and $\mathrm{O} 2127$ (Yonenobu and Eckstein, 2006) were previously developed, while NFI was newly developed in this study. The grids with dotted and blue lines show the gridded land air temperature data (CRUTEM4) (Jones et al., 2012) used for the calibration trials and the final calibration, respectively.

nal reconstruction. The statistical methods used in evaluating the reconstruction were Pearson's correlation, the reduction of error (RE), coefficient of efficiency (CE), and the sign test. A positive RE or CE indicates a valid reconstruction (Cook et al., 1994). Positive values for the sign test denote the correct sign for the reconstruction (Fritts, 1976). A residual analysis was also performed using the Durbin-Watson statistic and first-order autocorrelation $\left(\mathrm{AR}_{1}\right)$ for the residuals of the final reconstruction.

The final calibration model is below:

$T_{t}^{\mathrm{MAM}}=0.12 \mathrm{PC}_{t}+0.26 \mathrm{PC} 2_{t}-0.06$,

where $T_{t}^{\mathrm{MAM}}$ is March-May mean land temperature over the $35-40^{\circ} \mathrm{N}, 125-140^{\circ} \mathrm{E}$ region. The model accounts for $19.4 \%$ of the total variance and passes all the calibration tests (Table 2). A residual analysis demonstrates that the residuals due to regression show no significant autocorrelation $\left(\mathrm{DW}=1.939, \mathrm{AR}_{1}=0.03\right)$. The split models also passed the statistical tests $(p<0.05$ or positive RE/CE except for the CE slightly below zero). Intervention analysis was applied to the reconstruction to identify significant regime shifts $(p<0.05)$, in which the mean values of $15 \mathrm{yr}$ periods were compared on either side of each year (Rodionov, 2004).

Figure 3a shows the visual comparison between the estimated and actual mean March-May gridded temperature over the $35-40^{\circ} \mathrm{N}, 125-140^{\circ} \mathrm{E}$ region. A pronounced upward trend for the unfiltered actual CRUTEM4 data is observed, leading to the divergence between the actual and estimated CRUTEM4 data, despite their fairly good agreement of year-to-year variations. This trend is mostly eliminated for the filtered CRUTEM4 data. Thus, our reconstruction 
Table 1. List of chronologies.

\begin{tabular}{llllc}
\hline Region & Site ID & Location & Species $^{\mathrm{a}}$ & Ref. No. $^{\mathrm{b}}$ \\
\hline C. Korea & STR & $38^{\circ} 07^{\prime} \mathrm{N}, 128^{\circ} 28^{\prime} \mathrm{E}$ & TACU & 1 \\
& SPR & $38^{\circ} 07^{\prime} \mathrm{N}, 128^{\circ} 28^{\prime} \mathrm{E}$ & PIKO & 1 \\
& BTR & $36^{\circ} 57^{\prime} \mathrm{N}, 128^{\circ} 29^{\prime} \mathrm{E}$ & TACU & 1 \\
C. Japan & O2127 & $35^{\circ} 46^{\prime} \mathrm{N}, 137^{\circ} 30^{\prime} \mathrm{E}$ & CHOB & 2 \\
W. Japan & $\mathrm{JAPA001}^{\circ}$ & $35^{\circ} 20^{\prime} \mathrm{N}, 135^{\circ} 44^{\prime} \mathrm{E}$ & CMJA & 3 \\
& $\mathrm{JAPA007}^{\circ}$ & $35^{\circ} 20^{\prime} \mathrm{N}, 135^{\circ} 44^{\prime} \mathrm{E}$ & CMJA & 3 \\
NE Japan & NFI & $40^{\circ} 23^{\prime} \mathrm{N}, 140^{\circ} 17^{\prime} \mathrm{E}$ & CMJA & 4 \\
\hline
\end{tabular}

a TACU: Taxus cuspidata; PIKO: Pinus koraiensis; CHOB: Chamaecyparis obtusa; CMJA: Cryptomeria japonica. ${ }^{\text {b }}$ 1: Choi et al. (1994); 2: Yonenobu and Eckstein (2006); 3: Kojo (1987); 4: this study.

is considered to be skillful in estimating interannual-tointerdecadal variations and not for long-term change.

\section{Results}

\subsection{Correlations between principal components and temperature data}

PC1 correlates significantly with spring and summer temperature (positive), whereas PC2 correlates significantly with spring temperature (positive) and previous summer temperature (negative) (Fig. 2). According to the loadings of the correlation matrix in the principal component analysis (data not shown), PC1 (29.0\% of the variance) represents the Korean chronologies, while PC2 (25.3\% of the variance) represents the Japanese chronologies. Therefore, in this study, the geographic pattern is more significant than the difference between species. Moreover, the correlation coefficients between the PCs and mean March-May gridded temperature over the $35-40^{\circ} \mathrm{N}, 125-140^{\circ} \mathrm{E}$ region are $0.423(p<0.01)$ for PC1 and 0.225 for PC2 $(p<0.05)$, respectively.

\subsection{Reconstructed northeast Asian spring temperature}

Figure $3 \mathrm{~b}$ shows the reconstructed mean March-May gridded temperature over the $35-40^{\circ} \mathrm{E}, 125-140^{\circ} \mathrm{N}$ region with an interdecadal variation obtained by a $10-y r$ Gaussian filter. The $1887-1990$ mean $\left(-0.065^{\circ} \mathrm{C}\right)$ is shown to display cold and warm periods. The reconstructed northeast Asian spring temperature (R-NAST) demonstrates abrupt interdecadal fluctuations including below-average cold times within periods II (1807-1828), III (1829-1847) and V (1902-1922). Specifically, the cold periods identified were 1807-1820 (period II), 1835-1846 (period II), and 1904-1919 (period V), respectively. Higher interannual fluctuation can be observed in periods II and III (1820s-1830s). Period IV shows lower interdecadal variability, indicating slightly above average temperature. The intervention analysis generated six regime shifts at 1807, 1821, 1835, 1847, 1904, and 1919, giving a consistent result with the above-mentioned cold periods (Fig. 3b).

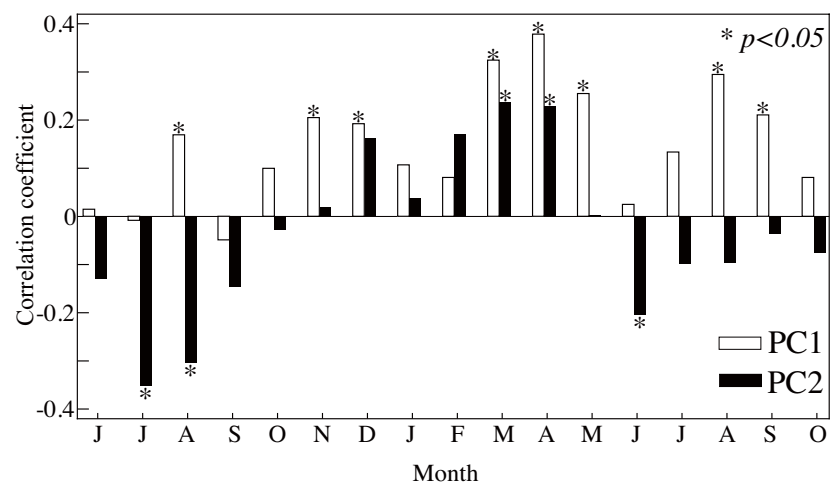

Fig. 2. Correlations between principal components and the mean March-May land temperature over the $35-40^{\circ} \mathrm{E}, 125-140^{\circ} \mathrm{N}$ study region.

\subsection{Comparison between R-NAST and the regional reconstructions}

R-NAST largely corresponds to the regional spring temperature reconstructions in Japan and Korea (Fig. 3c-f), despite the differences of estimated months. Figure $3 \mathrm{c}$ shows a 31-yr interval moving correlation between R-NAST and the regional reconstructions. The three reconstructions demonstrate positive significant correlations $(p<0.05)$ for most of the common interval (1784-1990), indicating high coherency. The four reconstructions display remarkably similar interdecadal fluctuations in periods II and III, with a coldwarm-cold pattern in each. Common interdecadal variations are also observed in periods IV and V; period IV shows lower interdecadal variations near the average temperature, and period $\mathrm{V}$ shows cold intervals. On the contrary, a divergence is observed among the reconstructions in period I; those in Japan show a cold period, and those in Korea and R-NAST show a relatively warm period.

\section{Comparison with other proxy records}

\subsection{Documentary records}

Documentary reconstructions show good agreements with our results. Fukaishi and Tagami (1992) reconstructed frequencies of a winter-type pressure pattern across Japan from old records over the period of 1720-1869, and suggested that extraordinarily cold conditions occurred during 18081819 (II) and 1826-1841 (III). Frequencies of the winter monsoon weather patterns across Japan during the 19th century were also estimated from old records by a different method, indicating a period of cool conditions in 1824-1841 (Hirano and Mikami, 2007).

A spring temperature reconstruction from historical documents for the Pacific coastal region of southern China shows a cold period from the 1790 s to the 1840 s, with a short-term 
Table 2. Calibration and verification statistics for the northeast Asian March-May temperature reconstruction.

\begin{tabular}{llll}
\hline Calibration & $1887-1990$ & $1887-1938$ & $1939-1990$ \\
\hline$R$ & 0.458 & 0.407 & 0.509 \\
$\mathrm{a} R^{2}$ & 0.194 & 0.132 & 0.229 \\
$\mathrm{RE}$ & 0.21 & 0.166 & 0.259 \\
$\mathrm{ST}$ & $73+/ 31-$ & $36+/ 16-$ & $35+/ 17-$ \\
\hline Verification & & $1939-1990$ & $1887-1938$ \\
\hline$R$ & & 0.484 & 0.393 \\
$\mathrm{a} R^{2}$ & & 0.234 & 0.155 \\
$\mathrm{RE}$ & & 0.184 & 0.121 \\
$\mathrm{CE}$ & & 0.019 & -0.040 \\
$\mathrm{ST}$ & & $38+/ 14-$ & $34+/ 18-$ \\
\hline
\end{tabular}

$R$ : correlation coefficient; a $R^{2}$ : explained variance after adjustment for degrees of freedom; RE: reduction of error; CE: coefficient of efficiency; ST: sign test result. Final calibration: $T_{t}^{\mathrm{MAM}}=0.12 \mathrm{PCl}_{t}+0.26 \mathrm{PC} 2_{t}-0.06$.

warm period around the 1820s (Wang et al., 1991). This finding agrees well with our reconstruction (I-III). Annual temperature reconstruction for eastern China using a 14 document-based series (Ge et al., 2007) also partially supports our reconstruction, in which the Little Ice Age continued from the 1770s to the end of the 19th century. Their result is consistent with our reconstruction in the first half of the 19th century (I-III), but not in the second half (IV).

\subsection{Recovered instrumental records}

Recovered instrumental records (March-May) for west Japan spring temperature (WJST) (Zaiki et al., 2006) show cold periods in the 1830 s and the 1880 s, and a short warming in the 1850s. These trends show notably good agreement with R-NAST except for the cold period of the 1880s, which, nevertheless, corresponds well to the Japanese reconstructions (Fig. 3e-f). This cold period is likely to be regionally limited to Japan. Actually, the correlation between February-April temperature for central Japan (Fig. 3e) and WJST $(r=0.542, p<0.001)$ is higher than that between RNAST and WJST $(r=0.382, p<0.001)$ for the period of 1863-1990.

\subsection{Other reconstructions and historical episodes}

R-NAST might contribute to describing the past behavior of the EAM. The reconstruction of the December-February Siberian High Index (SHI) (1599-1980) (D'Arrigo et al., 2005a) is generally consistent with R-NAST, particularly in the late 17 th and the early 18 th centuries (I-III). This is not the case in the 1830s, however, when little association is found between R-NAST and the extended East Asian Winter Monsoon Index (EAWMI) as computed from the SHI and the North Pacific Index (NPI) (D'Arrigo et al., 2005b); correlation between EAWMI and R-NAST is not significant. This

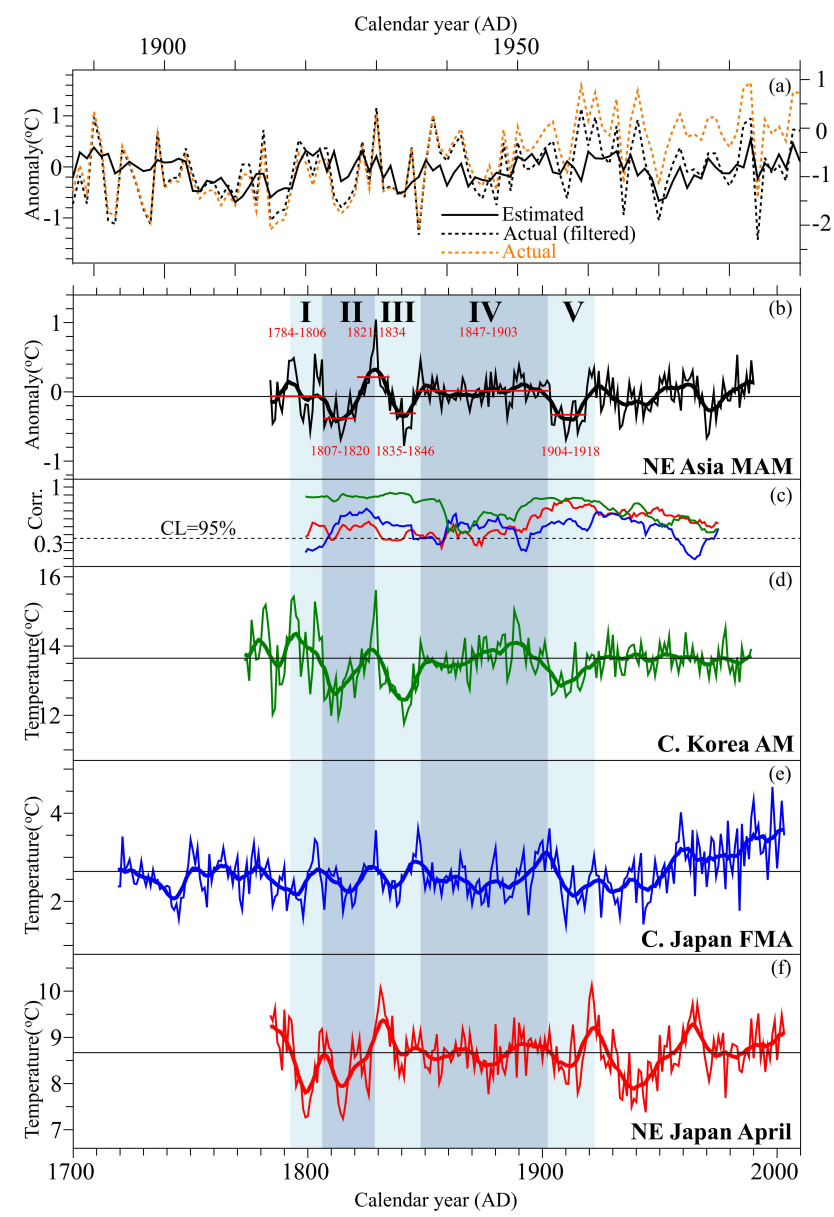

Fig. 3. (a) Estimated (solid line) and actual (dotted line) MarMay (MAM) temperature anomalies for northeast Asia. The actual record (orange line) is prewhitened to fit the low-frequency variability to the estimated series (see black dotted line). The left axis is for filtered actual and estimated records; the right axis for the actual record. (b) Reconstructed spring (MAM) temperature for northeast Asia. The horizontal red lines show regime shifts detected using intervention analysis (Rodionov, 2004). (c) 31-yr running correlations between R-NAST and the regional reconstructions (d-f): (d) C. Korea, April-May (Choi et al., 1994), (e) C. Japan, FebruaryApril (Yonenobu and Eckstein, 2006), (f) NE Japan, April temperatures (this study).

fact may be attributed to the seasonal difference between RNAST (March-May) and EAWMI (December-February).

Our reconstruction and the regional chronologies do not show any abrupt depression after the Tambora (1816) volcanic eruption (Fig. 3b, d-f). R-NAST exhibits the lowest temperature anomaly in 1814 and an increasing trend after 1815 in period III. It is possible that the Tambora eruption did not influence tree growth of the spring temperature-sensitive species we investigated. Moreover, the Laki (1783) eruption is also not detected in R-NAST.

A great famine occurred between 1832 and 1839 in Japan (Nishimura and Yoshikawa, 1936). Although famines in 
premodern Japan have generally been attributed to lower summer temperature (which caused bad crops of rice), our reconstruction shows spring temperatures in Korea and Japan were also cold in the prolonged famine period (period III).

\section{Conclusions}

We have reconstructed the mean March-May temperature over $35-40^{\circ} \mathrm{E}, 125-140^{\circ} \mathrm{N}$ for the period of $1784-1990$ using dendroclimatic reconstruction. The reconstruction captured spring temperatures for this region rather well at interannual to interdecadal $(<60 \mathrm{yr})$ time scales, and showed interdecadal fluctuations remarkably similar to the regional dendroclimatic reconstructions in Japan and Korea, indicating the past coherent spatial variations of the spring temperatures across the region. In spite of the low explained variance $(\sim 20 \%)$ for our reconstruction, we believe the result is remarkable because corresponding temperature fluctuations have been demonstrated across the region including the Korean Peninsula and the Japanese archipelago. Our reconstruction shows fairly good agreement with cold periods estimated from documentary records in eastern China and Japan. The recovered west Japan temperature series also showed a reasonable agreement with this reconstruction. Accordingly, these comparisons revealed that spatial climatic reconstruction from the tree-ring chronologies in this area offers a good potential to provide a proxy record for long-term, large-scale past temperature patterns for northeast Asia. Further studies for reconstructing broader-scale climate should be conducted in northeast Asia including northeast China, in which the spatial coverage of chronologies is improved (Zhu et al., 2009).

\section{Supplementary material related to this article is available online at: http://www.clim-past.net/9/261/2013/ cp-9-261-2013-supplement.pdf.}

Acknowledgements. This study was partly supported by KAKENHI (grant nos. 19700664, 17200050, 22500974, 21101002 and 23240116). We thank Rosanne D'Arrigo for providing SHI and EAWMI data for comparison. We are indebted to Katsuhiko Takata, Akita Prefectural University, for his support and useful comments in collecting samples, and to Richard Staff, RLAHA, University of Oxford, for English correction.

Edited by: E. Zorita

\section{References}

Choi, J.-N., Park, W.-K., and Yu, K.-B.: Central Korea temperature changes reconstructed from tree rings of subalpine conifers: A.D. 1635 to 1990, Dendrochronologia, 12, 33-43, 1994.

Cook, E. R., Briffa, K. R., and Jones P. D.: Spatial regression methods in dendroclimatology: a review and comparison of two techniques, Int. J. Climatol., 14, 379-402, 1994.
D'Arrigo, R. D., Jacoby, G., Wilson, R., and Panagiotopoulos, F.: A reconstructed Siberian High index since A.D. 1599 from Eurusian and North American tree rings, Geophys. Res. Lett., 32, L05705, doi:10.1029/2004GL022271, 2005a.

D’Arrigo, R. D., Wilson, R., Panagiotopoulos, F., and Wu, B.: On the long-term interannual variability of the East Asian winter monsoon, Geophys. Res. Lett., 32, L21706, doi:10.1029/2005GL023235, 2005b.

Davi, N., D’Arrigo, R., Jacoby, G., Buckley, B., and Kobayashi, O.: Warm-season annual to decadal temperature variability for Hokkaido, Japan, inferred from maximum latewood density (AD 1557-1990) and ring width data (AD 1532-1990), Climate Change, 52, 201-217, doi:10.1023/A:1013085624162, 2002.

Fritts, H. C.: Tree Rings and Climate, Academic Press, London, 567 pp., 1976.

Fukaishi, K. and Tagami, Y.: An attempt of reconstructing the winter weather situations from 1720-1869 by the use of historical documents, in: Proceedings of the International Symposium on the Little Ice Age Climate, Department of Geography, Tokyo Metropolitan University, Tokyo, 194-201, 1992.

Ge, Q., Zheng, J., Tian, Y., Wu, W., Fang, X., and Wang, W.: Coherence of climatic reconstruction from historical documents in China by different studies, Int. J. Climatol., 28, 1007-1024, doi:10.1002/joc.1552, 2007.

Gostev, M., Wiles, G., D’Arrigo, R., Jacoby, G., and Khomentovsky, P.: Early summer temperatures since 1670 A.D. for Central Kamchatka reconstructed based on a Siberian larch tree-ring width chronology, Can. J. Forest Res., 26, 2048-2052, 1996.

Hirano, J. and Mikami, T.: Reconstruction of winter climate variations during the 19th century in Japan, Int. J. Climatol., 28, 1423 1434, doi:10.1002/joc.1632, 2007.

Jacoby, G., Solomina, O., Frank, D., Eremenko, N., and D’Arrigo, R.: Kunashir (Kuriles) Oak 400-year reconstruction of temperature and relation to the Pacific Decadal Oscillation, Palaeogeogr. Palaeocl., 209, 303-311, doi:10.1016/j.palaeo.2004.02.015, 2004.

Jones, P. D., Lister, D. H., Osborn, T. J., Harpham, C., Salmon, M., and Morice, C. P.: Hemispheric and large-scale land-surface air temperature variations: An extensive revision and an update to 2010, J. Geophys. Res., 117, D05127, doi:10.1029/2011JD017139, 2012.

Kojo, Y.: A dendrochronological study of Cryptomeria japonica in Japan, Tree-Ring Bull., 47, 1-21, 1987.

Maejima, I. and Tagami, Y.: Climate of Little Ice Age in Japan, Geographical Reports of Tokyo Metropolitan University, 18, 91$111,1983$.

Nishimura, M. and Yoshikawa I. (Eds.): Nippon Kyokoshi Ko, Maruzen, Tokyo, an archival collection of disasters in Japan, 1936 (in Japanese).

Rodionov, S. N.: A sequential algorithm for testing climate regime shifts, Geophys. Res. Lett., 31, L09204, doi:10.1029/2004GL019448, 2004.

Wang, R., Wang, S., and Fraedrich, K.: An approach to reconstruction of temperature on a seasonal basis using historical documents from China, Int. J. Climatol., 11, 381-392, 1991.

Yonenobu, H. and Eckstein, D.: Reconstruction of early spring temperature for Central Japan from the ring widths of Hinoki cypress and its verification by other proxy records, Geophys. Res. Lett., 33, L10701, doi:10.1029/2006GL026170, 2006. 
Zaiki, M., Können, G., Tsukahara, T., Jones, P., Mikami, T., and Matsumoto, K.: Recovery of nineteenth-century Tokyo/Osaka meteorological data in Japan, Int. J. Climatol., 26, 399-423, doi:10.1002/joc.1253, 2006.
Zhu, H. F., Fang, X. Q., Shao, X. M., and Yin, Z. Y.: Tree ringbased February-April temperature reconstruction for Changbai Mountain in Northeast China and its implication for East Asian winter monsoon, Clim. Past, 5, 661-666, doi:10.5194/cp-5-6612009, 2009. 